\title{
Rene Lefebre, Horreur et ressemblance chez Maupassant
}

\section{Marco Garrone}

\section{(2) OpenEdition}

1 Journals

\section{Edizione digitale}

URL: https://journals.openedition.org/studifrancesi/38117

DOI: 10.4000/studifrancesi.38117

ISSN: 2421-5856

\section{Editore}

Rosenberg \& Sellier

\section{Edizione cartacea}

Data di pubblicazione: 15 décembre 2004

Paginazione: 639-640

ISSN: 0039-2944

\section{Notizia bibliografica digitale}

Marco Garrone, «Rene Lefebre, Horreur et ressemblance chez Maupassant», Studi Francesi [Online], 144 (XLVIII | III) | 2004, online dal 30 novembre 2015, consultato il 08 mai 2021. URL: http://

journals.openedition.org/studifrancesi/38117 ; DOI: https://doi.org/10.4000/studifrancesi.38117

Questo documento è stato generato automaticamente il 8 mai 2021.

\section{(c) $(1) \&$}

Studi Francesi è distribuita con Licenza Creative Commons Attribuzione - Non commerciale - Non opere derivate 4.0 Internazionale. 


\title{
Rene Lefebre, Horreur et ressemblance chez Maupassant
}

\author{
Marco Garrone
}

\section{NOTIZIA}

RENE LEFEBRE, Horreur et ressemblance chez Maupassant, «Travaux de Littérature», XIII, 2000, pp. 227-245.

1 L'importanza in M. di temi come il doppio e l'altro, lo specchio, e la presenza di elementi stilistici come la ridondanza narrativa sono di fatto riconosciuti in M.: quello che si propone l'A. non è semplicemente riesporre lo studio di tali tematiche: attraverso l'analisi di alcuni dei racconti e delle novelle dello scrittore naturalista si intende infatti tracciare una sorta di fenomenologia della ressemblance, principio fondante secondo cui ci sarebbero delle copie più o meno precise di qualsiasi elemento esistente nella nostra realtà. Partendo da questo l'A. procede in primo luogo col cogliere in modo più preciso il senso tragico di cui ogni opera è pregna, per poi riconoscervi successivamente l'altro grande tema, l'orrore.

2 Ed è proprio l'orrore della vita, elemento da cui si parte e a cui inevitabilmente si tende, ad essere particolarmente legato al concetto di follia, quella forza liberatrice che, proprio come il suicidio, svincola dalla ripetizioni e dalle costrizioni. La follia, ci spiega l'A., in M. è un secondo mondo, un mondo senza leggi, un universo in cui a particolari cause non corrispondono precise conseguenze, un altrove affascinante al quale si ha accesso attraverso "l'abominevole tortura dello specchio". Questo semplice oggetto, il cui ruolo viene infatti immediatamente preso in considerazione, cela in sé una forza indicibile: riflettendo la nostra immagine lo specchio ci rappresenta, svela la contingenza della nostra realtà così simile da ciò che la ragione può ponderare e così diversa anche da ciò che un altro oggetto, il ritratto ad esempio, può portarci illusoriamente a pensare. Di fronte allo specchio i personaggi di M. vivono un'esperienza strana, esso rivela la verità, sia felice sia (più spesso) crudele: esso ci 
introduce in sostanza ad una realtà ancora più orribile di quella che i nostri occhi sono in grado di percepire.

3 L'efficacia dello specchio interferisce tuttavia con quella del ritratto e della fotografia: se lo sdoppiamento catottrico rivela cosa siamo o, come nel caso di Le Horla, ci permette di conoscere l'inconnu, nel caso del ritratto, ancora più pessimisticamente, non ci resta che scoprire attraverso di esso l'inevitabile cambiamento, cosa eravamo e cosa ora non siamo più. In seguito all'analisi del processo di ressemblance all'interno della novella sopraccitata e in un altro racconto, Lui, e tracciando frequenti paralleli con altre novelle cronologicamente precedenti, l'A. analizza poi il rapporto tra l'alterità autoscopica e la conseguente creazione di fantasmi portatori di verità terribili e distruttrici. I personaggi dei testi brevi di M. sono talvolta perfino tentati di riconoscere come vera l'immagine del ritratto, rinnegando l'essenza della realtà stessa. Questo pessimismo, che genera inevitabilmente anche realismo e dunque orrore, porta l'A. ad avvicinare M. al filosofo tedesco Schopenhauer.

4 Presa in oggetto è poi anche la ressemblance di tipo familiare, la più frequente. Di matrice naturalista, questo tipo di somiglianza è forse la peggiore: in racconti come Le champ d'oliviers e Un fils, essa diventa motore per un'amara scoperta, e caricandosi di una forza accusatoria, ci pone di fronte la nostra vera natura e la gravità dei errori del nostro passato. La somiglianza, ancora una volta, non si mostra dunque che come causa di orrore, soprattutto quando essa implica la ripetizione di un qualcosa che di per sé non è che atroce. Già nella ripetizione vizio e sofferenza si perpetuano, vivere diventa allora veder perpetuare l'errore e la colpa.

5 La somiglianza, che viene definita come la linea che separa la realtà dal fantastico e da ciò che sembra ma che non esiste, ci rivela dunque quanto orribile sia effettivamente l'esistenza. Dell'orrore quotidiano che riempie la nostra vita, che si trova in ogni piccolezza e che si proietta all'origine di quella "nausée des habitudes" non può allora che scaturire follia pura.

6 Alla luce di quanto fin qui detto sembrerebbe quindi ovvio che la non-assomiglianza non può non essere che una fortuna. Questo non è totalmente vero, ed è l'A. stesso a portarcene una prova: molto raramente, infatti, assomigliarsi vuol dire anche appartenere ad un tipo, possedere un tratto comune ad un altro da sé che testimonia la nostra esistenza, fornendo allo stesso tempo la sicurezza dell'esistenza di un altro mondo (di platonica memoria) a cui la nostra immagine tende ed aspira.

7 Tuttavia, sebbene la ressemblance sia vista come il legame più prezioso tra due entità, essa non è altro che un segno di trascendenza, di povertà, un segno che ci ricorda ancora una volta che siamo soggetti ad invecchiamento psichico e fisico; a questo processo di mimesis di tipo esistenziale si aggiunge un sentimento artistico che purtroppo prolunga, attraverso la coscienza, l'orrore dell'esistenza. E dall'orrore nasce la follia, intesa, dice l'A., come la triste consapevolezza della nostra ragione di non poter aspirare a qualcosa di più alto che non sia il calvario che già viviamo: "siamo nati per vivere più per la materia che per lo spirito, ma il nostro spirito, a forza di pensare, ha creato una sproporzione tra la nostra intelligenza accresciuta e le nostre condizioni di vita immutate". 